\title{
Attitude Control of Small Probes for De-orbit, Descent and Surface Impact on Airless Bodies Using a Single PWM Thruster
}

\author{
Michael Gillham and Gareth Howells \\ School of Engineering and Digital Arts, University of Kent, Canterbury, England, UK \\ Corresponding contact: M.Gillham@kent.ac.uk
}

\begin{abstract}
A single thruster attitude and de-orbital control method is proposed, capable of delivering a small spin stabilized probe with payload to the surface of an airless body such as the Moon. Nutation removal, attitude control and fast large angle maneuvers have been demonstrated and shown to be effective using a commercially available single standard cold gas pulse width modulated controlled thruster model. Maximum final impact angle due to drift and residual velocities was found to be less than 5 degrees and the maximum angle of attack to be $4 \mathrm{deg}$. The conventional 3-axis control would require as many as twelve thrusters requiring a more substantial structure with complex pipework, and a more sophisticated controller. The single thruster concept minimises the mass requirement and thus cost of the mission, making the concept of small networked surface probes for extended science missions more viable. Experiments based on computer simulation have shown that strict design and mission profile requirements can be fulfilled using the single thruster control method.
\end{abstract}

Keywords - single thruster; attitude control; surface penetrator; air-less body; space network; communication; navigation

\section{INTRODUCTION}

$\mathrm{T}$ here has been recent renewed activity in solar system exploration and exploitation, private companies and even competitive competitions, spurred on by proposals to establish permanent manned bases within and beyond the Earth-Moon system [1], [2]. Ever increasing collaboration between agencies and countries bring ever greater resources together to meet the challenges of these goals. One area of research has been the study of using planetary penetrator probes to augment rover surface exploration; a significantly broader and deeper field of study then becomes possible from a single mission [3].

Penetrators are defined as kinetic low mass probes which can impact the surface of a planetary body at a velocity sufficient so as to penetrate the surface to a depth up to a few meters, it is proposed that the penetrator could be left protruding the surface which would allow these probes to be additionally used as a communications relay and to provide a fixed navigation beacon.

Previous mission proposals such as Lunar-A, MoonLITE and Lunar-Glob included a proposal for penetrators, this platform type was deemed necessary in order to accomplish the required science objectives. The UK MoonLITE mission proposal's main goal was to be seismic detection hence investigating the lunar internal structure. Infra-red spectroscopic sensors capable of volatile substance analysis, which would be invaluable data for any long term lunar manned presence [4].

The Lunar-A, Institute of Space and Astronautical Science (ISAS), proposal in 1995 [5] proposed obtaining sub surface temperature measurements to determine uranium abundance and thus refractory metal composition of the lunar interior, this method might also be a useful tool for exploitation of resources for mining operations. Lunar-Glob was the Russian proposal whose science goals also planned to investigate the lunar refractory materials and volatiles [6].

Research into these penetrator platforms has led to several technical challenges; platform stability, attitude and rhumb line control, sensor response time and inertial navigation whilst maintaining an effective mass and cost budget.

This paper investigates a low-cost minimal hardware approach system-level design capable of delivering a penetrator to the surface of an airless body, whilst observing attitude requirements and the de-orbit profile required to keep the payload intact when impacting the surface.

\section{MISSION PROFILE REQUIREMENTS}

In order to minimise overall mission mass and cost the lunar penetrator requires an optimal release and de-orbit profile. The angle between the longitudinal axis of the lunar penetrator and the flight path velocity vector at the time of impact should be no more than eight degrees [7] to prevent penetrator structural integrity collapse. Numerous previous surface penetration tests for Lunar-A had set the upper boundary for impact velocity to around $330 \mathrm{~m} / \mathrm{s}$ and a nominal velocity of $285 \mathrm{~m} / \mathrm{s}$ to ensure adequate penetration depth into the lunar regolith [8]. Lunar surface impact angle was also deemed to be optimal when orthogonal [9]; these tests carried out by the ISAS concluded that an impact with an 11 degree angle of attack and $305 \mathrm{~m} / \mathrm{s}$ velocity would result in a $3 \mathrm{~m}$ penetration depth with a final rest angle 54 degrees from horizontal.

The angles of attack and impact therefore represent critical parameters for consideration in attitude system design, final 
velocity requirement and angle of impact error can be minimised by choosing the correct altitude and orbital parameters from which to de-orbit the penetrator.

Penetrator attitude control essentially requires pitch axis control with a fast re-orientation large angle nutation minimised manoeuvre and occasional yaw correction with the third axis spin stabilised. A rapid de-orbit velocity change together with active nutation damping are also required.

\section{SINGLE THRUSTER CONCEPT}

A rotating rocket projectile showed that using a low cost MEMS gyroscope, and an extended Kalman filter, angular rate measurements could be used to control the attitude of a spin stabilised rocket through the use of single shot solid motor thrusters mounted on the body [10]. An early paper in the Lunar-A proposal determined that the system needed to be as simple and mass economical as possible whilst maintaining adequate precision, hence restrictions on the availability of instruments and actuators. They concluded that the only option was to use rhumb line control [7].

The Lunar-A penetrator relied on a single sun sensor and accelerometer as instrumentation with a single cold gas nitrogen thruster. The sun sensor was to provide a platform rotational pulse and sun angle used to compute the rhumb line orthogonal manoeuvre. The accelerometer would provide disturbance feedback to enable the pulse of the thruster to be timed to perform the precession.

The extensive Lunar-A modelling culminated in flight testing on board an ISAS sounding rocket (S-520-18) in January 1997 which reached an apogee of $309 \mathrm{~km}$ [11]. The control method they adopted was to use a compensated time delay algorithm, based on accelerometer feedback. This feedback improved the estimated contribution to the angle of attack from 0.7 degrees to an experimentally proven value of 0.1 degrees, reducing the final angle of attack to within the empirical criterion of 8 degrees [11].

Spinning spacecraft may be controlled through the use of nutation free precession moments [12]-[14]. A pair of pulses fired from the same thruster at some calculable time separation, as long as no other thruster firing occurs during the time interval can be used to provide nutation free precession [13]. Active nutation control can be achieved to a satisfactory degree by introducing a controlled nutation to the system which then acts to cancel the existing nutation [13].

The Euler equations of torque coupling can be used to define two pulses fired from the same thruster half the nutation period apart, the pitch $\omega_{y}$ and yaw $\omega_{z}$ velocities without inducing nutation as follows;

$$
\begin{aligned}
& \omega_{y}=\frac{F \Delta t \Delta_{m}}{I_{t}} \cos \left(\omega_{n u t} t\right)-\frac{F \Delta t \Delta_{m}}{I_{t}} \sin \left(\omega_{n u t} t\right) \\
& \omega_{z}=\frac{F \Delta t \Delta_{m}}{I_{t}} \sin \left(\omega_{n u t} t\right)+\frac{F \Delta t \Delta_{m}}{I_{t}} \cos \left(\omega_{n u t} t\right)
\end{aligned}
$$

$$
\begin{aligned}
\theta(t)= & \frac{F \Delta t \Delta_{m}}{h_{x}} I_{t} \sin \left(\omega_{\text {nut }} t\right) \\
& +\frac{F \Delta t \Delta_{m}}{h_{x}}\left[\cos \left(\omega_{\text {nut }} t\right)-1\right] \\
\psi(t)=- & \frac{F \Delta t \Delta_{m}}{h_{x}}\left[\cos \left(\omega_{\text {nut }} t\right)-1\right] \\
& +\frac{F \Delta t \Delta_{m}}{h_{x}} I_{t} \sin \left(\omega_{\text {nut }} t\right)
\end{aligned}
$$

Where:

Thruster force, $\mathrm{N}=F \Delta$

Momentum arm, $\mathrm{m}=\Delta_{m}$

Pulse time $=\Delta t$

Nutation frequency $=\omega_{\text {nut }}$

Transverse inertia $I_{y}=I_{z}=I_{t}$

As the nutation period is known we can identify the parameters of the nutation motion by obtaining the Fourier coefficients of the waveform from instrumentation. Some angular bias $\theta_{k \sim}$ can simultaneously be removed with the nutation error by the application of two pulses $t_{1}$ and $t_{2}$ consecutively applied with reference to the phase shift $\alpha$ if we take the correctional waveform as;

$$
\theta(t)=\theta_{k \sim}+\theta_{\text {nut }} \sin \left(\omega_{\text {nut }} t+\alpha\right)
$$

It then follows that if these two pulses are activated with an angular interval $\delta$ then according to Equations 3 and 4 the angular steady state control history can be described from "(5)" as follows [13];

$$
(5) \Rightarrow \theta_{c}=A \sin \left(\omega_{\text {nut }} t\right)+B \cos \left(\omega_{\text {nut }} t\right)+C
$$

Where;

$$
\begin{aligned}
& A=\frac{\Delta h_{y}}{h_{x}} \sqrt{\frac{I_{z}}{I_{y}}}[1+\cos \delta]+\frac{\Delta h_{z}}{h_{x}} \sin \delta \\
& B=-\frac{\Delta h_{y}}{h_{x}} \sqrt{\frac{I_{z}}{I_{y}}} \sin \delta+\frac{\Delta h_{z}}{h_{x}}[1+\cos \delta] \\
& C=-2 \frac{\Delta h_{z}}{h_{x}}
\end{aligned}
$$

If we also define;

Then;

$$
D=\left(\frac{\Delta h_{y}}{h_{x}}\right)^{2} \frac{I_{z}}{I_{y}}+\left(\frac{\Delta h_{z}}{h_{x}}\right)^{2}
$$

$$
A^{2}+B^{2}=\theta_{\text {nut } c}^{2}=2 D[1+\cos \delta]
$$

Where in order to cancel the nutation we need to create a controlled nutation with amplitude $\theta_{\text {nut } c}=\theta_{\text {nut }}$ the time between the two pulses is then given by;

$$
\Delta t=\frac{\cos ^{-1}\left(\frac{\theta_{\text {nut }}^{2}}{2 D}-1\right)}{\omega_{\text {nut }}}
$$


If $t_{0}$ is defined as the time when $\theta(t)-\theta_{k \sim}=0$ then the first pulse $t_{l}$ must be fired at;

$$
t_{1}=\frac{\tan ^{-1}(B / A)}{\omega_{\text {nut }}}
$$

The minimum impulse bit is limited by the thruster coil opening and spring closing hysteresis, a minimum acceptable value is in the order of $10 \mathrm{~ms}$ (Marotta SV06), the maximum impulse is limited by the maximum thruster effective pulse width. This has a dependency on the cosine of the angle of half the pulse width angle $\Delta \theta / 2$ as the pulse width tends to $2 \pi$ the effectiveness of momentum precession tends to zero with a maximum possible effective pulse width at $\pi / 2$ [14].

\section{PROPOSED SINGLE THRUSTER CONTROL SYSTEM}

Nutation free precession can be achieved by firing the two timed pulses in exact phase with the rotational and nutation frequency which is traditionally maintained by careful control of the rotational velocity requiring additional hardware and control such as a momentum wheel or more thrusters. An airless body penetrator mission profile however has a sequence of events to action and at each stage the rotational rate, momentum arm, and inertia matrix of the penetrator is different whilst also in turn changing with respect to time during each phase. The penetrator platform thus requires a simple computationally inexpensive control solution.

The mission requirement for these penetrators is of a sufficient short duration that cyclical external disturbances can be ignored and providing that the thruster paired pulsing is as close to the nutation half period as possible any coupling will be minimal and well within the gyroscopic stability. Thus the slow build-up of nutation and any yaw component can be effectively and timely removed using the nutation damping equations long before any significant instability arises.

In order to solve the unbalanced rotation to nutation ratio thruster pulse-pair [7] the Lunar-A proposed to use a pulsewidth pulse-amplitude method which involved the design and construction of a complex and expensive thruster valve capable of modulating the pulse profile width and thrust. This research develops a method which uses an industry standard pulse width modulated bang-bang type thruster such as the Marotta SV06 to control the attitude and to perform a fast rhumb line manoeuvres.

In order to keep the pair of pulses balanced they must be both fired so that the second pulse completely cancels the precession started by the first pulse. This can be achieved by firing the first pulse, such that the midpoint of the thruster pulse width acts as if it were fired at time $\mathrm{T}$ shown in Fig. 1 and the subsequent second pulse is similarly fired at a time $\mathrm{T} \varepsilon$ when the thruster is orthogonally aligned with the precession path as close to the half nutation period as possible which gives an attitude arc length of $\underline{A}$ with a residual angular error $\varphi \varepsilon a$.

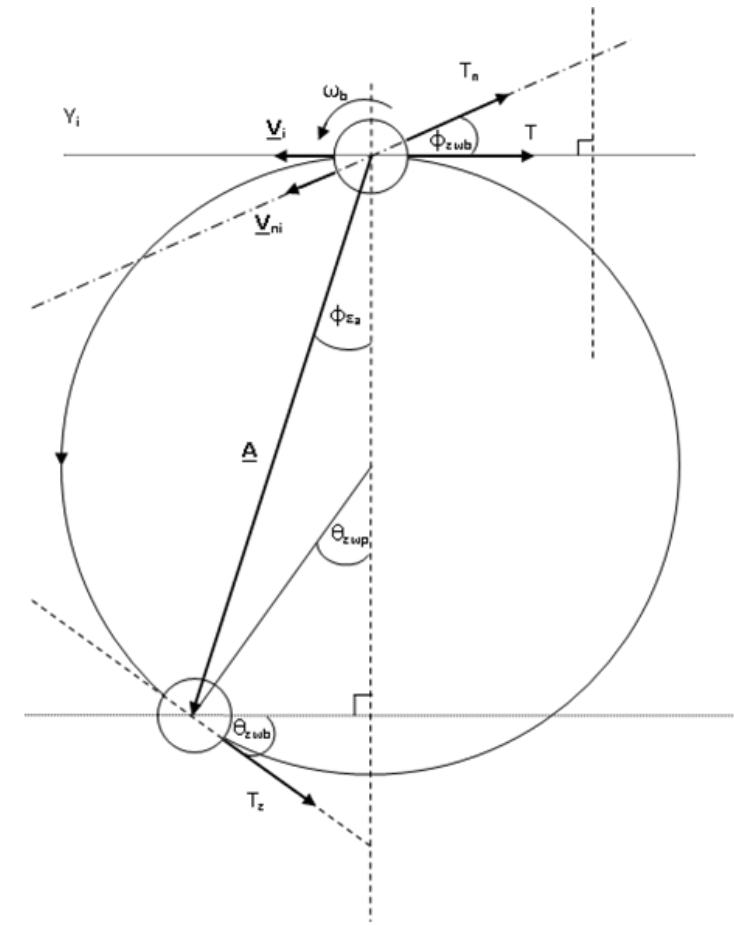

Fig. 1. Precession motion viewed from the end of the penetrator

When the demand from the attitude controller calls for an angular attitude change $A_{T}$ the maximum impulse $\varphi_{\text {imp }}$ is first calculated, then from updated look up tables maximum $\mathrm{A}$ is calculated, $\mathrm{A}_{\mathrm{T}}$ is divided by the maximum A value to obtain the number of whole attitude pulse pair changes are required, the remainder is also calculated and this value is then used to determine $\varphi_{\text {imp }}$ for the final pulse pair.

$$
\begin{gathered}
\operatorname{Max} \varphi_{i m p}=\mathrm{f}_{(\mathrm{t})} \pi / 2 \omega \mathrm{b} \\
\operatorname{Max} \mathrm{A}=\frac{\operatorname{Max} \varphi_{i m p} \mathrm{~L}}{\mathrm{I}_{\mathrm{x}} \omega_{\mathrm{x}}} \\
\text { Number of Max A pulse pairs }=\text { Floor }\left|\frac{\mathrm{A}_{\mathrm{T}}}{\operatorname{Max} \mathrm{A}}\right| \\
\text { Remainder of Max A pulse pairs = Modulo }\left|\frac{\mathrm{A}_{\mathrm{T}}}{\operatorname{Max} \mathrm{A}}\right|=\mathrm{r}
\end{gathered}
$$

$$
\text { Final A pulse pair } \varphi_{i m p}=\mathrm{rH}_{(\mathrm{x})} / \mathrm{L}
$$

$\mathrm{T}=\mathrm{t}_{\mathrm{m}}$ and is the midpoint thruster direction alignment for the first firing, orthogonal to and in the rotational direction $\left(\omega_{\mathrm{b}}\right)$ of the direction in which the force acts:

$$
\Delta \mathrm{t}=\mathrm{f}_{(\mathrm{t})} / \varphi_{i m p}
$$

Essentially the alignment of $\mathrm{T}$ is orthogonal to the required attitude change direction. The second pulse of the pair $\mathrm{T}_{\varepsilon}$ will have an error component due to the non-integer ratio between the body rotation axis and the nutation period. The timing of second thruster firing midpoint $\mathrm{t}_{\mathrm{m}}$ coincides with $\mathrm{T}_{\varepsilon}$ when $\theta_{\varepsilon \omega \mathrm{p}}=$ 
$\theta_{\varepsilon \omega \mathrm{b}}$ where this is solved iteratively for efficient attitude mode as follows:

$$
\begin{gathered}
\sin \omega_{\mathrm{b}} \mathrm{t}=\tan \omega_{\text {nut }} \mathrm{t} \\
\mathrm{t}<\left(\text { floor }\left|\frac{\omega_{\mathrm{b}}}{\omega_{\text {nut }}}\right|\right) \pi / \omega_{\mathrm{b}} \\
\mathrm{t}>\left\{\left(\text { floor }\left|\frac{\omega_{\mathrm{b}}}{\omega_{\text {nut }}}\right|\right)-1 / 4\right\} \pi / \omega_{\mathrm{b}}
\end{gathered}
$$

Fast attitude mode; $\sin \omega_{b} t=\tan \omega_{\text {nut }} t$

$$
\text { Boundaries }
$$

$$
\begin{gathered}
\tan \omega_{\text {nut }}<|1| \\
\omega_{\mathrm{b}}>\pi<3 / 2 \pi \\
\text { Rhumb line; } \\
\sin \omega_{\mathrm{b}} \mathrm{t}=5 / 4 \pi \\
\tan \omega_{\text {nut }}=3 / 4 \pi \mp 0.05
\end{gathered}
$$

Due to the imbalance in the rotation nutation ratio an attitude error occurs which can be corrected on subsequent firings. The next non rhumb line firing $T_{n}$ must be separated by a stabilisation time of $2 / \omega_{\text {nut }}(\pi-2)$ plus the attitude error from the previous pairing as follows:

$$
\begin{gathered}
\text { Where: } \varphi_{\varepsilon \omega \mathrm{b}}=\varphi_{\varepsilon \mathrm{a}}=1 / 2 \theta_{\varepsilon \omega \mathrm{p}} \\
\sin \omega_{\mathrm{b}} \mathrm{t}=1 / 2 \sin \omega_{\text {nut }} \mathrm{t} \\
\text { Boundaries } \\
\mathrm{t}>\left(\text { floor }\left|\frac{\omega_{\mathrm{b}}}{\omega_{\text {nut }}}\right|\right) \pi / \omega_{\mathrm{b}}+\left(\text { ceiling }\left|\frac{(\pi-2) \omega_{\mathrm{b}}}{\pi \omega_{\text {nut }}}\right|\right) 2 \pi / \omega_{\mathrm{b}} \\
\mathrm{t}<\left(\left(\text { floor }\left|\frac{\omega_{\mathrm{b}}}{\omega_{\text {nut }}}\right|\right)+1 / 4\right) \pi / \omega_{\mathrm{b}}+ \\
\left(\text { ceiling }\left|\frac{(\pi-2) \omega_{\mathrm{b}}}{\pi \omega_{\text {nut }}}\right|\right) 2 \pi / \omega_{\mathrm{b}}
\end{gathered}
$$

However for the fast rhumb line manoeuvre the only delay is $\tau_{\mathrm{c}}$ where the timing $\mathrm{T}_{\mathrm{n}}$ is:

$$
\begin{gathered}
\sin \omega_{\mathrm{b}} \mathrm{t}=1 / 2 \sin \omega_{\text {nut }} \mathrm{t} \\
\mathrm{t}>\left(\text { floor }\left|\frac{\omega_{\mathrm{b}}}{\omega_{\text {nut }}}\right|\right) \pi / \omega_{\mathrm{b}}+\tau \\
\mathrm{t}<\left\{\left(\text { floor }\left|\frac{\omega_{\mathrm{b}}}{\omega_{\text {nut }}}\right|\right)+1 / 4\right\} \pi / \omega_{\mathrm{b}}+\tau
\end{gathered}
$$

Where $\tau$ is the time of the nearest integer number of full body rotations greater than the required thruster coil cooling off period $\tau_{\mathrm{c}}$ determined by the manufacturer of the standard thruster used:

$$
\tau=\left(\text { ceiling }\left|\frac{\tau_{c} \omega_{\mathrm{b}}}{2 \pi}\right|\right) 2 \pi / \omega_{\mathrm{b}}
$$

These control pulses do not contribute to the nutation of the platform, however due to uncertainties and disturbances there will be an unwanted nutation build up.

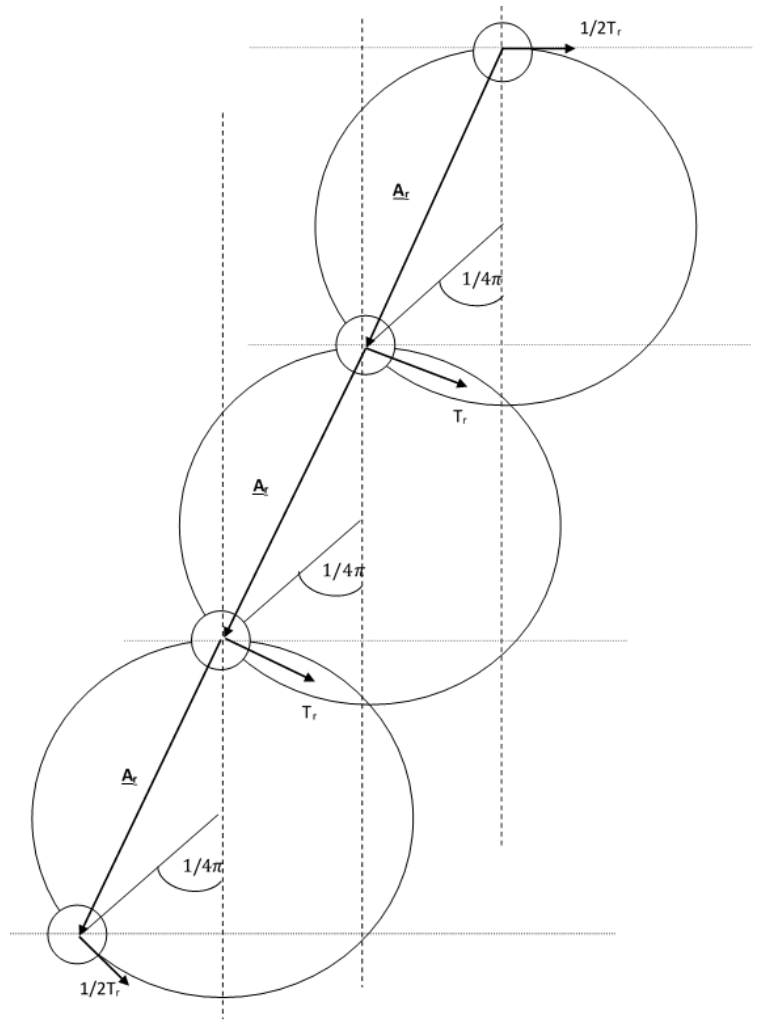

Fig. 2. Rapid rhumb line manoeuvre

\section{SIMULATION RESULTS}

TABLE.1 LUNAR PENETRATOR MASS AND INERTIA VALUES USED FOR SIMULATION

\begin{tabular}{lr}
\hline Penetrator platform total mass & $33 \mathrm{~kg}$ \\
Payload mass & $13 \mathrm{~kg}$ \\
AOCS total dry mass & $1 \mathrm{~kg}$ \\
AOCS propellant mass & $0.584 \mathrm{~kg}$ \\
De-orbit motor total mass & $18 \mathrm{~kg}$ \\
Epoch inertia values $\left[\mathrm{I}_{\mathrm{xx}}, \mathrm{I}_{\mathrm{yy}}, \mathrm{I}_{\mathrm{zz}}\right]$ & {$[0.385,11,11] \mathrm{kg} \mathrm{m}^{2}$} \\
Inertia after de-orbit $\left[\mathrm{I}_{\mathrm{x}}, \mathrm{I}_{\mathrm{yy}}, \mathrm{I}_{\mathrm{zz}}\right]$ & {$[0.119,5.916,5.916] \mathrm{kg} \mathrm{m}^{2}$} \\
Inertia (after motor separation) $\left[\mathrm{I}_{\mathrm{xx}}, \mathrm{I}_{\mathrm{yy}}, \mathrm{I}_{\mathrm{zz}}\right]$ & {$[0.065,5.416,5.416] \mathrm{kg} \mathrm{m}^{2}$} \\
Inertia at impact $\left[\mathrm{I}_{\mathrm{xx}}, \mathrm{I}_{\mathrm{yy}}, \mathrm{I}_{\mathrm{zz}}\right]$ & {$[0.056,4.458,4.458] \mathrm{kg} \mathrm{m}^{2}$} \\
Epoch distance from COM to thruster & $0.170 \mathrm{~m}$ \\
De-orbit distance from COM to thruster & $0.291 \mathrm{~m}$ \\
Descender distance from COM to thruster & $0.503 \mathrm{~m}$ \\
Impactor distance from COM to thruster & $0.554 \mathrm{~m}$ \\
\hline
\end{tabular}

Penetrator mass distribution and inertia values are similar to those used in both the Lunar-A and the MoonLITE mission proposals shown in Table 1 which were used to generate a cylindrical model in Solid Works ${ }^{\mathrm{TM}}$ particular consideration was given to modelling the centre of mass as it changes over time in order to give proper consideration to the thruster momentum arm. This has enabled a better simulation of the torque and linear velocity components, and disturbance effects throughout the mission profile. The cold gas propellant ISP used for the simulations was nitrogen. 
The following parameters were used in the simulation:

- Momentum arm $0.503 \mathrm{~m}$

- Thruster force $10 \mathrm{~N}$

- H vector $2.229 \mathrm{Nms}$

- Nutation period $15.263 \mathrm{~s}$

- Ratio of torque to inertial 0.95/0.05

- Pulse width $0.045 \mathrm{~s}$

- Rotational rate 34.3 radians/s

- Impulse $0.16 \mathrm{Nms}$

The penetrator attitude control keeps the projectile body axis aligned with the trajectory, when the orbital control determines the time for descent the de-orbit solid fuel motor is ignited and the orbital velocity is reduced to almost zero such that the penetrator now falls almost vertically accelerating under gravity to the surface, the altitude will determine the impact velocity and the time for the rhumb line manoeuvre.

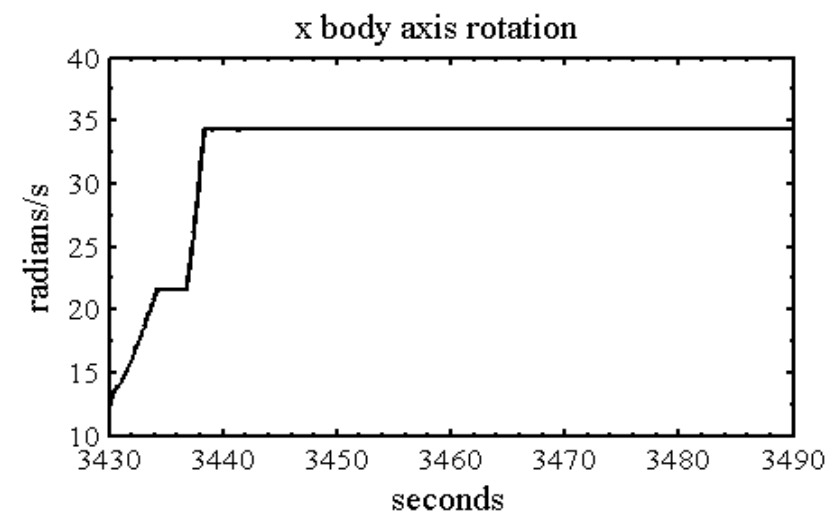

Euler yaw angle nutation

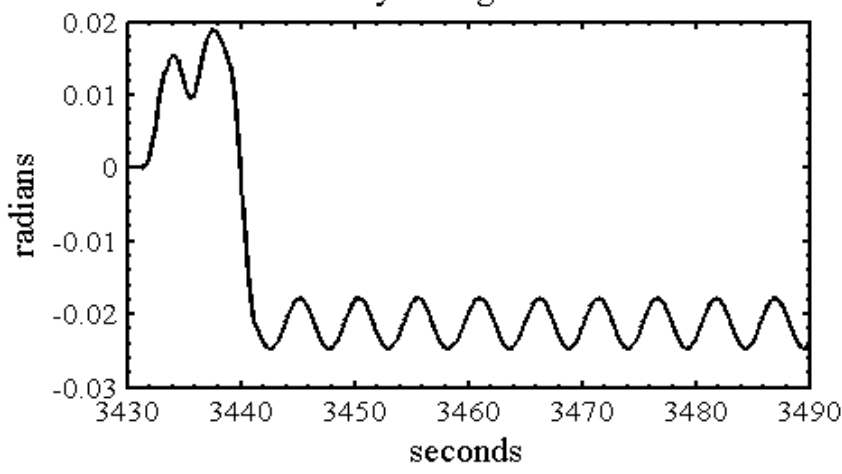

Fig. 3. Spin up of penetrator during solid motor combustion and case discard

The penetrator was given an initial rotational stability of $4 \pi$ radians/s and the simulation, shown in Fig. 3, indicated that the penetrator rotational velocity will increase to 34.3 radians/s as a result of mass ejection during the solid motor burn and discard stages; as a result we therefore have a maximum, non-axes impinging, time period between any two orthogonal axes of
$45 \mathrm{~ms}$ for attitude control, or a maximum $90 \mathrm{~ms}$ half period for rhumb line firing. The nutation caused by the combustion and discard was analysed and shown in Fig. 3, the $0.85^{\circ}$ disturbance observed compares to the one degree of calculated amplitude. The simulation showed that the required velocity change for the solid motor burn duration, using typical performance values, to be 7.82 seconds; motor discard was set at $t_{0}+12 \mathrm{~s}$.

The residual nutation was then cancelled, shown in Fig. 4, then a rapid rhumb line manoeuvre initiated, this involves a rapid sequence of small angular precession changes, this manoeuvre can be carried out in a rapid succession where the pulses are separated by a $3 / 8$ of the nutation period, shown in Fig. 2, and no stabilization time. The maximum width thruster pulse can thus be fired repeatedly and almost in phase with the nutation period even without feedback control enabling a rapid change in penetrator attitude whilst minimizing any nutation.

Euler yaw and pitch angle nutation damping

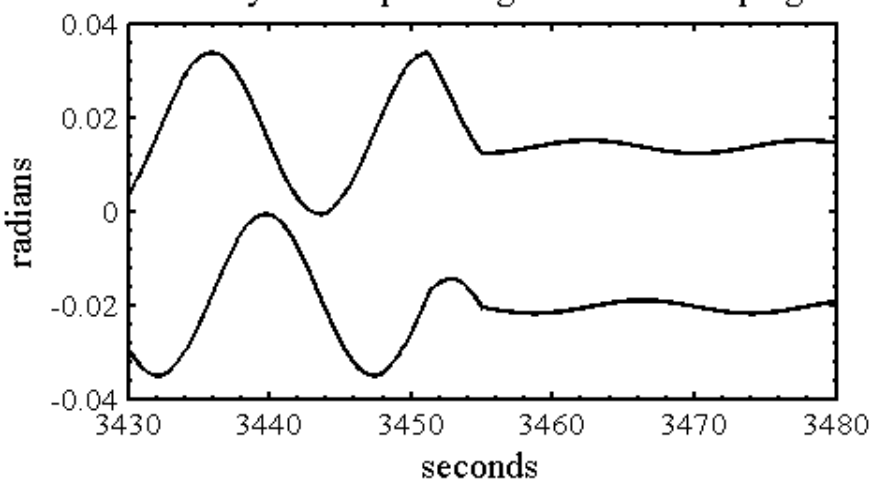

Thruster nutation damping pulses

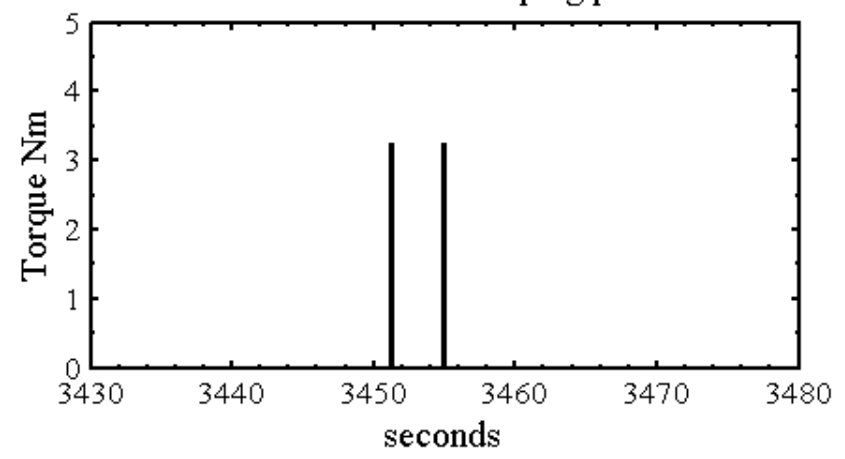

Fig. 4. Nutation pacification using paired thruster pulsing

If we take all the downrange and cross-range error velocities integrated over time from the orbit transfer and de-orbit, then we can obtain the angle of impact with the ground, where $90^{\circ}$ would be ideal. The angle calculated from the simulation results was found to be less than five degrees with an angle of attack of four degrees calculated from the remaining attitude error; both angles were less than previous mission criteria [7], [13]. The impact error ellipse is calculated from residual velocities causing drift and was found to be $8.3 \mathrm{~km} \times 6.8 \mathrm{~km}$, which was again within mission stated objectives [4], [13]. 


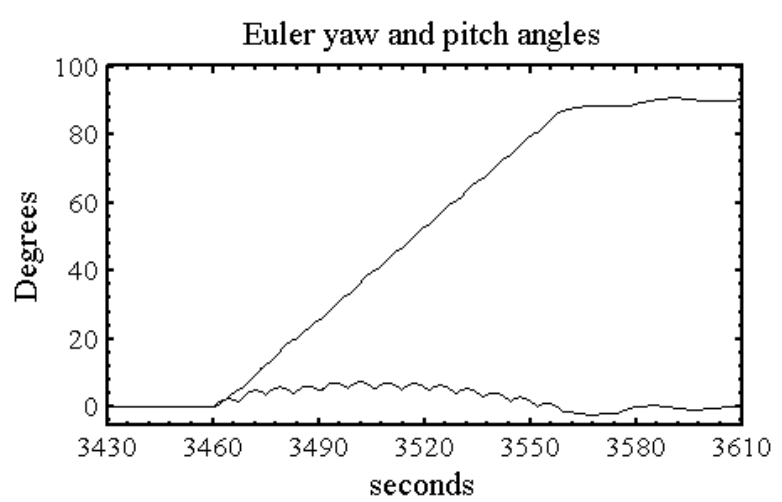

$\mathrm{y}$ and $\mathrm{z}$ axis thruster pulse

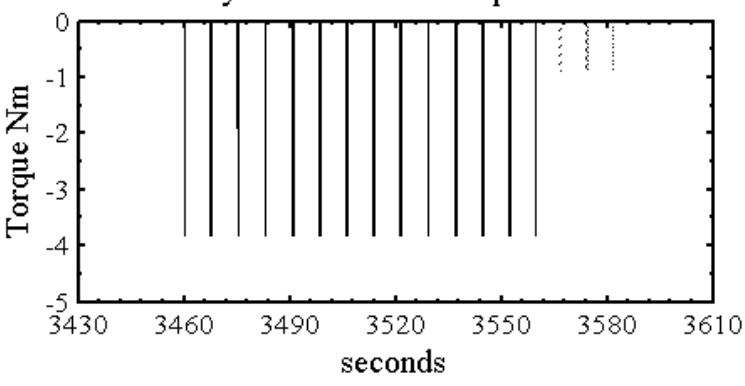

Fig. 5. These results show the continuous rapid firing rhumb line manoeuvre two pairs of smaller negative $\mathrm{z}$ axis final attitude correction pulses shown dashed

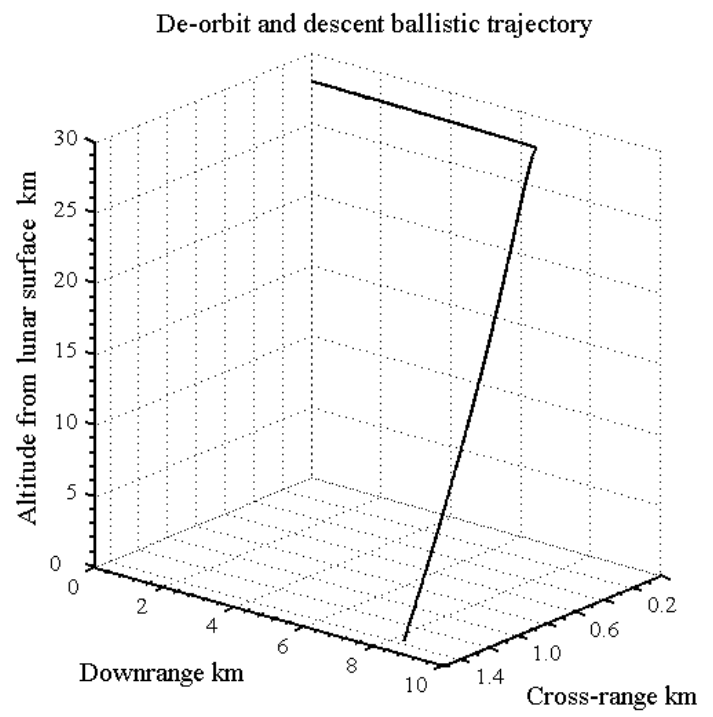

Fig. 6. Plot of the ballistic velocity vector

TABLE 1. LUNAR PENETRATOR CONTROL SIMULATION RESULTS SUMMARY

\begin{tabular}{cccccc}
\hline \hline $\begin{array}{c}\text { Control } \\
\text { phase }\end{array}$ & $\begin{array}{c}\text { Number } \\
\text { of Pulses } \\
\text { fired }\end{array}$ & $\begin{array}{c}\text { Maximum } \\
\text { angle of } \\
\text { control }\end{array}$ & $\begin{array}{c}\text { Total } \\
\text { angular } \\
\text { change }\end{array}$ & $\begin{array}{c}\text { Linear } \\
\text { velocity } \\
\mathrm{m} / \mathrm{s}\end{array}$ & $\begin{array}{c}\text { Mass of } \\
\mathrm{N} \text { gas } \\
\mathrm{kg}\end{array}$ \\
\hline Orbital & 360 & $0.506^{\circ}$ & $91^{\circ}$ & 4.048 & 0.236 \\
Rhumb & 26 & $6.9^{\circ}$ & $90^{\circ}$ & 0.0351 & 0.153 \\
Attitude & 4 & $1.3^{\circ}$ & $3.9^{\circ}$ & 0.0024 & 0.0001 \\
Nutation & 2 & $0.92^{\circ}$ & $0.92^{\circ}$ & - & - \\
\hline \hline
\end{tabular}

\section{CONCLUSION}

The ability to simplify the design of the attitude control of the penetrator along the pitch and yaw axes offers major advantages both in simplicity of design and associated cost savings increasing the potential utility of the design. The paper has shown how this goal can be achieved using a single standard cold gas thruster controlling both axes simultaneously by using only timed pulses. The simulations have shown that the nutation component caused by the ratio imbalance is small and is controllable using active nutation damping.

The rhumb line large angle attitude manoeuvre has been proven, in simulation, to be practically achievable during the limited descent time period using a single thruster with rapid pulsing. Sufficient time remained for further nutation damping and fine attitude adjustment prior to impact. The final angle of attack was found to be less than $4^{\circ}$ and the angle of impact orthogonal to the surface less than $5^{\circ}$ which would be improved by using sensor feedback to the control.

The major conclusion of the paper is therefore that a single bang-bang thruster can be applied to high velocity rapid deployment space missions and contribute to the development and design of smaller low-cost space probes.

\section{REFERENCES}

[1] L. Hansen. Paving the path for human space exploration: The challenges and opportunities. Johnson Space Centre May 2016 https://ntrs.nasa.gov/archive/nasa/casi.ntrs.nasa.gov/20160006002.pdf

[2] C. P. McKay. The case for a NASA research base on the moon. New Space 1(4), pp. 162-166. 2013.

[3] Ball, Andrew, et al. Planetary landers and entry probes. Cambridge University Press, 2007

[4] Gao, Y. et al Lunar Science with Affordable Small Spacecraft Technologies: MoonLite and Moonraker, Planetary and Space Science, 56:368-377, 2007

[5] H. Mizutani. Lunar interior exploration by Japanese lunar penetrator mission, LUNAR-A. Journal of Physics of the Earth 43pp. 657-670. 1995.

[6] E. Galimov. Luna-glob project in the context of the past and present lunar exploration in Russia. Journal of Earth System Science 114(6), pp. 801806. 2005.

[7] Y. Morita et al. Control systems of the LUNAR-A penetrator. Strengthening Cooperation in the 21 St Century: proceedings of the 6th International Space Conference of Pacific-Basin Societies (ISCOPS, formerly PISSTA) held December 6-8, 1995, Marina Del Rey, California, USA. Vol. 91. Amer Astronautical Society, pp. 823-835. 1996.

[8] H. Mizutani et al. Lunar-A Penetrator: ITS Science and Instruments. Penetrometry in the Solar System, Austrian Academy of Sciences Press, Vienna (2001), pp. 125-136

[9] Shiraishi, H. et al, The Present Status of the Japanese Penetrator Mission: Lunar-A, Journal of Advances in Space Research, 2007.

[10] Anderson, A. et al, Investigation of Mal-launch Correction in SpinStabilised Rockets, IEEE Southeast Conference Proceedings, 267-272, 2007.

[11] Y. Morita et al. Attitude control of the LUNAR-A penetrator system and its flight test. Advances in the Astronautical Sciences 96pp. 853-864. 1997.

[12] Wertz, J.R. Spacecraft Attitude Determination and Control. D. Reidel Publishing Company, Dordrecht Holland, 1978.

[13] M. J. Sidi. Spacecraft Dynamics and Control: A Practical Engineering Approach 1997.

[14] Chobotov, V. Spacecraft Attitude Dynamics and Control, original edition. Krieger Publishing Company, Florida USA, 1991.

[15] M. H. Kaplan. Modern spacecraft dynamics and control. New York, John Wiley and Sons, Inc., 1976.427 p. 11976. 